\title{
Los antropónimos femeninos latinos de origen griego de la Península Ibérica*
}

\author{
Araceli Striano \\ Universidad Autónoma de Madrid \\ araceli.striano@uam.es

\section{Latin Feminine Personal Names of Greek origin coming from the Iberian Peninsula}

\begin{abstract}
La presencia de nombres propios de origen griego en las inscripciones latinas de la Península Ibérica es notable. Abarca además un amplio período cronológico que se extiende en el tiempo como demuestra la documentación medieval procedente de iglesias y centros religiosos. El artículo muestra que la adaptación fonética y morfológica de estos nombres en latín se produjo de forma limitada, lo que justifica que la variedad de las formas de estos nombres griegos no conociera una expansión fuera del círculo cerrado de individuos que los llevaron en su momento.
\end{abstract}

Palabras clave: nombres propios griegos; adaptación fonética; adaptación morfológica; epigrafía latina.
The presence of Greek Personal Names in the Latin inscriptions coming from the Iberian Peninsula is considerable. Furthermore, from the evidence found in religious centres it is clear that these inscriptions comprise a broad chronological period reaching to Medieval times. This paper shows that the Phonetic and Morphological adaptation of these names was very limited in Latin. Consequently, the fact that the various forms of these Greek names did not expand outside the closed community which bore them is justified.

Key words: Greek Personal Names; Phonetic adaptation; Morphological adaptation; Latin epigraphy.

* El texto de este artículo fue presentado como comunicación en el XXIV Congreso Internacional de ICOS sobre Ciencias Onomásticas, Barcelona, 5-9 de septiembre de 2011 y se enmarca dentro del proyecto de investigación FFI2010-21807. Agradezco las observaciones y sugerencias de Beatriz Moncó Taracena que sin duda han mejorado el resultado final de este estudio. Doy las gracias asimismo a Claude Brixhe con quien he hablado en reiteradas ocasiones sobre este tema, así como a los autores anónimos de los informes elaborados para la revista, algunas de cuyas observaciones y consejos he incluido con gusto en mi trabajo. 
1. Los instrumentos que están a disposición del estudioso de la antroponimia griega se han acrecentado notoriamente en los últimos tiempos. La recopilación llevada a cabo en los volúmenes del Lexicon of Greek Personal Names $(L G P N)^{1}$ permite contar con un corpus exhaustivo de nombres propios griegos que resulta indispensable para su observación y estudio.

El mayor número de ejemplos procede naturalmente de las inscripciones de las diferentes regiones que formaron parte de la antigua Grecia a lo largo de los tiempos. Después de Grecia, los nombres griegos de las inscripciones latinas de Roma constituyen la otra fuente más importante para su estudio ${ }^{2}$. Evidentemente se trata de un material de distinta naturaleza. Por una parte, contamos con los testimonios directos escritos en alfabeto griego (en alfabetos epicóricos en las inscripciones más antiguas) y por otra, con otros transcritos en alfabeto latino y adaptados a la estructura fonética y morfológica de esta lengua.

A pesar de la lejanía geográfica entre Grecia y la Península Ibérica los datos epigráficos de nombres propios griegos de esta última no son nada desdeñables, de hecho, podemos considerar sin temor a equivocarnos que son los siguientes en importancia tras los de Grecia y Roma.

En primer lugar, contamos con los ejemplos de las inscripciones griegas de la Península. Aunque el número de documentos redactados en griego es escaso $^{3}$ y no es esperable a priori la presencia de ejemplos que sean diferentes de los ya conocidos en Grecia y Roma, podemos encontrarnos con alguna sorpresa verdaderamente llamativa. Así sucede, por poner un ejemplo conocido, en el caso de 'Epнокóḯко procedente de una lista de NP de una defixio de Ampurias de finales del siglo IV a.C., en cuya formación se encuentran yuxtapuestos los nombres de dos ríos de Asia Menor, el Hermo y el Caico cercanos a Focea, la metrópoli de la colonia ${ }^{4}$.

${ }^{1}$ El objetivo de este proyecto es la recopilación de todos los nombres propios griegos que aparecen en las fuentes epigráficas desde el siglo VIII a.C. hasta los últimos años de la época imperial romana. La mejor información del proyecto se encuentra en su página web, http://www.lgpn.ox.ac.uk/.

${ }^{2}$ Los ejemplos han sido recopilados y estudiados por Solin 1996 y 2003.

${ }^{3}$ La mejor información actualizada de las inscripciones griegas de la Península se encuentra en los trabajos de de Hoz 1997, Rodríguez Somolinos 1998 y Canós i Villena 2002.

${ }^{4}$ El nombre en cuestión fue estudiado por Louis Robert poco tiempo después de la publicación de la inscripción a cargo de Martín Almagro en 1952. Robert retomó su análisis posteriormente y más tarde Olivier Masson lo emparejó con el nombre muy similar de un

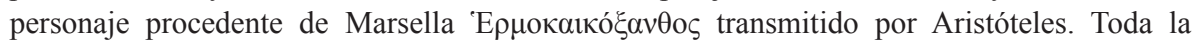
información al respecto se encuentra en Curbera 1997. 
En segundo lugar, disponemos de un buen conjunto de nombres propios griegos de las inscripciones latinas de Hispania. También en este caso nos hemos encontrado con algunos nombres sin parangón en Grecia o Roma ${ }^{5}$.

En este estudio, sin embargo, no es nuestra intención intentar añadir más nombres de este tipo a la lista general. Nos proponemos analizar los mecanismos de adaptación fonética y morfológica de estos nombres griegos en latín. Para ello hemos restringido nuestro corpus a las inscripciones de Hispania y dentro de éste a los nombres propios femeninos que presentan peculiaridades específicas diferentes de los masculinos. Se trata de una muestra muy definida, pero estoy convencida de que los resultados que alcancemos serán aplicables al latín de Roma y a los ejemplos de las inscripciones procedentes de esta ciudad.

El empleo de estos nombres propios, cuyo mayor número de ejemplos se encuentra en inscripciones latinas, se prolonga en el tiempo hasta al menos el siglo XII de nuestra era. La mayor parte de los nombres que nos ocupan se atestiguan sin embargo en inscripciones fechadas entre los siglos I y IV d.C.

Los nombres propios procedentes de la Península atestiguados en las inscripciones latinas más antiguas fueron agrupados y estudiados por Arminda Lozano y los más recientes constituyen una parte de una investigación más amplia llevada a cabo recientemente por Lydia Becker ${ }^{6}$. Estos últimos ejemplos más tardíos proceden de la documentación que proporcionan los archivos de las catedrales y centros religiosos de la España medieval en un soporte por lo tanto distinto; es sabido que buena parte de los nombres propios de algunos de los mártires de la iglesia son de origen griego. Además, en el caso concreto de España, la presencia bizantina en el sureste de la península a lo largo de los siglos VI y VII supone una fuente directa de nombres propios griegos en esta época. Todo ello demuestra que la presencia de nombres propios griegos en la Península Ibérica cuenta con una tradición a lo largo de los siglos equiparable en buena medida únicamente a Italia.

Nuestro estudio se centrará sobre todo en los nombres propios procedentes de la documentación epigráfica. Los ejemplos medievales analizados por Becker pueden servir para vislumbrar en algunos casos el destino final de estos nombres, es decir, su posible supervivencia y continuidad en España.

${ }^{5}$ Cf. Striano 2004 y 2010.

${ }^{6}$ Lozano Velilla 1998 y Becker 2009. 
Además de los estudios mencionados, para analizar estos nombres propios contamos con otros instrumentos de trabajo imprescindibles para abordar cualquier estudio de esta índole. En primer lugar, hay que decir que la edición de las inscripciones latinas procedentes de Hispania ha conocido un nuevo impulso en los últimos años con la reedición del volumen CIL II ${ }^{2}$ 14, 1 y 2 (Conventus Tarraconensis), II 5 (Conventus Astigitanus), II ${ }^{2} 7$ (Conventus Cordubensis) y la recopilación de las ediciones de las nuevas inscripciones que siguen apareciendo en la revista Hispania Epigraphica. Ambas publicaciones cuentan con una página web excelente que constituye un instrumento muy valioso ${ }^{7}$ de búsqueda de documentación para el estudioso interesado, que consta al menos de la transcripción de la inscripción (en ocasiones de la traducción) y de su fotografía o facsímil, además de la referencia completa de la edición.

2. La metodología empleada en nuestro estudio está basada en la comparación en primer lugar de los nombres propios griegos de Hispania con los que proceden de las inscripciones latinas de Roma $^{8}$ en la idea de que son los paralelos más cercanos y el espejo en el que debemos mirar necesariamente: la transcripción y adaptación de estos nombres en latín debe ser obligatoriamente la misma, aunque no se puede descartar que los datos de Hispania puedan aportar algunos ejemplos específicos, particulares de esta zona que pueden estar ocasionalmente ausentes del corpus de Roma ${ }^{9}$. Además, resulta por otra parte evidente que los nombres propios griegos de Roma y de Hispania no deberían en principio alejarse demasiado en su forma de los atestiguados en Grecia, sobre todo si proceden de documentos epigráficos pertenecientes a una franja cronológica similar. La comparación en este caso se puede llevar a cabo mediante la consulta de la obra monumental de los catálogos de nombres propios griegos presentes en la obra colectiva $L G P N$.

A partir de la comparación entre estos diferentes corpora se puede analizar su formación, es decir, la raíz o base de los nombres y el sufijo que presentan. Una vez identificados los antropónimos desde el punto de vista morfológico (tarea que no siempre es sencilla), es posible estudiar las condicio-

7 Centro CIL II de la Universidad de Alcalá de Henares, http://www2.uah.es/imagines_cilii/ Hispania Epigraphica online database, http://www2.uah.es/imagines_cilii/.

${ }^{8}$ Solin 2003.

${ }^{9}$ Es el caso de los nombres Odephorus, Laurotiche y Tricisma, cf. Striano 2004 y 2010. 
nes de la adaptación fonética y morfológica de estos nombres propios griegos en latín, en concreto en el latín de Hispania.

3. La mayoría de los nombres propios griegos de Hispania atestiguados entre los siglos I-V de nuestra era proceden de inscripciones funerarias. Aparecen sobre todo en nominativo, en lo que podríamos considerar como caso neutro, es decir, el caso en el que usualmente se enumeran los nombres propios de los difuntos a quienes se hace referencia. Pueden presentarse asimismo también en genitivo (en la función de complemento de nombre) como propietarios del monumento funerario, o bien, en dativo (complemento indirecto) como beneficiarios del monumento que se ha erigido en su honor. Hay que señalar que se trata en la mayor parte de las ocasiones de nombres propios de esclavos ${ }^{10}$ de origen griego.

No deja de ser llamativo a nuestros ojos que estas personas de condición servil dispusieran de estelas funerarias en sus tumbas y que sus nombres constaran en ellas, lo que demuestra que debieron de tener consideración y aprecio social $^{11}$. Sus nombres griegos suelen ser sus cognomina y evidentemente delatan sus orígenes ${ }^{12}$, aunque es posible que no sea siempre necesariamente así ${ }^{13}$.

4. Por su condición lingüística ${ }^{14}$, sabemos que los nombres propios extranjeros pueden ser aceptados con más facilidad que otro tipo de palabras en las lenguas

10 Todos ellos se encuentran en el manual de Solin 1996. Conviene señalar no obstante que los nombres de los esclavos no se diferencian de los demás en general, ni siquiera en el uso de los adjetivos étnicos para llamarlos, cf. Masson 1973, p.13.

${ }^{11}$ Aunque en efecto la gran mayoría de ellos eran de condición servil, libertos o esclavos, conviene señalar la importancia y el prestigio social del que muchos de ellos gozaban: ejercían profesiones liberales e incluso algunos llegaron a las más altas esferas sociales, cf. Beltrán Fortes 2013. Debo esta importante observación, así como la referencia bibliográfica a Ma Paz de Hoz.

${ }^{12}$ El texto de las inscripciones responde usualmente al siguiente esquema: L(ucio) Sentio Carchedonio / Sentiae Thaliae / Sentia Carchedonia / filia , "para Lucio Sentio Carcedonio y Sentia Talía, su hija Sentia Carcedonia», en donde Sentius, Sentia responden al nombre de la familia y Carchedonius, Thalia y Carchedonia a los cognomina, CIL II²/14, 107 (Imagen en Hispania Epigraphica online).

${ }^{13}$ Cf. Beltrán Fortes 2013.

${ }^{14}$ Suelen analizarse desde un punto de vista lingüístico como una subclase derivada de los nombres comunes. Son nombres cuyo significado es la propia persona a la que hacen referencia o el lugar en el caso de los topónimos. Tienen además connotaciones extralingüísticas evidentes en el sentido de que se eligen en buen medida por motivos ajenos a su significado etimológico, salvo en el caso de los que son de buen augurio, apotropaicos. 
en las que se presentan. En realidad, son préstamos lingüísticos que deben encontrar acomodo en la lengua que los recibe. Otra de las características de esta clase de palabras es el hecho de que carecen de significado intrínseco ${ }^{15}$. Por ello, teniendo en cuenta que su significado hace referencia a sujetos concretos e individuales, son especialmente sensibles a distintas modas, lo que puede provocar su éxito instantáneo en un momento determinado en cualquier contexto social. Es por ello que parece que pueden adaptarse, ser acogidos y aceptados con mayor facilidad que otros préstamos lingüísticos. Subyace también en este caso el hecho de que no es necesaria (o por lo menos no tan necesaria) la convención y el acuerdo social en la elección del nombre propio que se quiera asignar a un hijo, de tal manera que el componente individual en esta elección es mucho mayor que en el caso del resto de las palabras que componen una lengua.

Resulta evidente que la irrupción de los nombres propios griegos en latín debió de acarrear unas consecuencias innegables de orden lingüístico en esta lengua:

(a) sin duda los nombres griegos debieron de dar lugar a la aparición de nuevos sonidos desconocidos en latín que tuvieron que adaptarse a las características fonéticas y fonológicas de esta lengua. Es el caso de las consonantes aspiradas del griego ${ }^{16}$, inexistentes en latín, o la vocal / ̈̈/ del dialecto jónico-ático, por poner dos ejemplos emblemáticos ${ }^{17}$;

(b) generaron nuevas terminaciones para los nombres de mujer y de hombre distintas de las que había en latín, así como la presencia de sufijos de apariencia extraña y ajena a la lengua latina.

Es muy probable que estos sonidos y formaciones nuevos tuvieran su impacto lingüístico en latín en su momento y que su permanencia y acepta-

\footnotetext{
${ }^{15}$ Fernández Leborans 1999, p. 86.

${ }^{16}$ Las convenciones para la transcripción de las consonantes aspiradas griegas en latín se basan en principio en el empleo de las grafías de las correspondientes consonantes sordas. Es muy posible que este uso gráfico respondiera a lo que llamamos grafía aproximada. Este uso alterna con otro de carácter más culto en el que aparecen estas consonantes sordas acompañadas de la notación de la aspiración $p h$, th, etc. Cuando las consonantes aspiradas del griego se fricativizaron, al menos la labial aspirada del griego podía transcribirse con la $f$ latina, cf. Biville 1990, pp. 137-140; 142-143 y 189-199.

${ }^{17}$ En el caso de las grafías que los latinos utilizaron para la /ü/ griega, hay que decir que la transcripción culta responde a $y$, pero que tanto $u$ como $i$ sirven también para ello, cf. Biville 1995, pp. 255-319.
} 
ción debió de depender de su capacidad para ser absorbidos y adaptados por esta lengua.

5. Para llevar a cabo el objetivo que nos hemos propuesto, hemos tenido en cuenta únicamente los nombres propios griegos de género femenino que constituyen una buena parte de la totalidad de los ejemplos. Es un corpus más específico y concreto, pero se puede afirmar sin temor al error que el peso de estos nombres sobre el total es a priori bastante llamativo en el sentido de que, aunque sería necesario sustentar nuestra afirmación con datos estadísticos, es cierto que la presencia de nombres de mujeres en las tumbas es más elevada que en Grecia (al menos en Grecia continental, no así en Asia Menor en donde abundan los nombres propios de mujeres en inscripciones funerarias). Este hecho constituye sin duda un aliciente añadido porque nos permite contar con un número mayor de ejemplos para el estudio de la formación del nombre propio griego de las mujeres.

Resulta de interés enumerar someramente las terminaciones más frecuentes de estos nombres femeninos de origen griego y ver cómo sobreviven en latín.

5.1. En griego las principales formaciones de nombres femeninos se agrupan en las siguientes terminaciones:

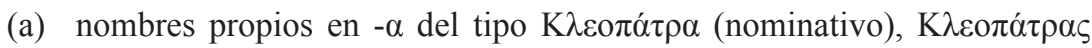

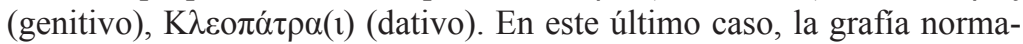
tiva en Grecia era $<\mathrm{AI}>$, aunque la más habitual es $<\mathrm{A}>^{18}$ en koiné;

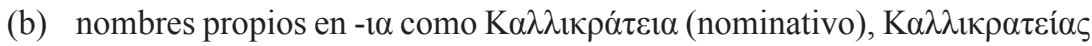

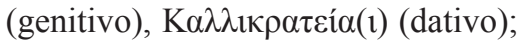

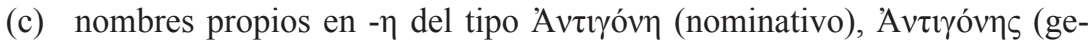

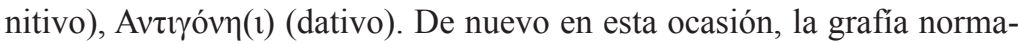
tiva era $\langle\mathrm{HI}>$, pero la habitual $<\mathrm{H}>$;

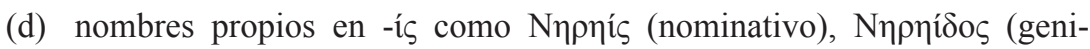

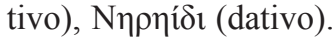

De entrada, parece claro que las posibilidades de adaptación fonética y morfológica de los nombres propios griegos femeninos son distintas en unos casos y en otros. Así, lo lógico y esperable es que los nombres propios feme-

\footnotetext{
${ }^{18}$ Como consecuencia de la monoptongación del diptongo largo en griego.
} 
ninos griegos en - $a$ y en -ia encajaran adecuadamente en el sistema morfológico del latín puesto que estas terminaciones son coincidentes en ambas lenguas.

Por el contrario, los nombres propios griegos en $-\eta(=$ e $)$ o los en -ís debieron de provocar un efecto extraño al oído de los hablantes de latín, de tener una apariencia necesariamente extranjera, puesto que no respondían al esquema que tenían los nombres femeninos en esta lengua.

5.2. Sabemos que los romanos sintieron desde el principio una gran admiración por la lengua y la cultura de los griegos de forma que tanto las imitaciones como las reacciones en contra del carácter claramente nacionalista se produjeron con frecuencia entre los escritores latinos y no son más que las dos caras de la misma moneda. La clase alta de la sociedad de Roma conocía muy bien las obras literarias griegas e incluso hablaba en griego. Desde siempre, desde los primeros contactos entre ambas culturas se fueron estableciendo unas convenciones gráficas que se respetaban a la hora de transcribir términos griegos en latín.

Así, sabemos que el diptongo griego $<\mathrm{AI}>$ se transcribe usualmente en latín como $<\mathrm{AE}>$, de manera que no es una sorpresa que los nombres griegos en $-a$ o en -ia aparezcan con esta terminación en las inscripciones latinas cuando se emplee el genitivo o el dativo.

Es el caso de los ejemplos del tipo Calchisiae (CIL II 5189), Thaliae (CIL II2/14, 107), Alexandriae (CIL II2/14, 49), Anthusae (CIL II2/14, 163), Atticae (CIL II2/14, 262), Pantherae (CIL II2/14, 156), Nymphidiae (CIL II2/14, 424), Eutychiae (CIL II 4987), etc.

5.3. Llama la atención el hecho de que esta convención gráfica se mantenga incluso en el caso del dativo en donde, tal y como hemos señalado, la terminación gráfica más frecuente en griego era en $-a$, porque el antiguo diptongo largo de dativo había monoptongado en la lengua de la koiné. Este hecho demuestra que estos nombres se han integrado aparentemente en la declinación latina sin problemas y presentan la terminación usual -ae de dativo y genitivo de los temas en $-a$ latinos.

Sin embargo, conviene tener presente que grafía y fonética no responden siempre a una misma realidad. De hecho, sabemos que en latín desde muy pronto el diptongo /ae/ monoptongó en una vocal larga de timbre /e/, y a pesar de todo conservó su representación gráfica, sobre todo en las terminaciones casuales $<\mathrm{AE}>$ como es nuestro caso. Es sabido que la ortografía de 
las marcas morfológicas ${ }^{19}$ es especialmente conservadora en la escritura de cualquier lengua, y es lógico que los lapicidas de Roma o Hispania las respeten siempre si tenemos en cuenta que eran más fáciles de recordar que las que se encuentran en otros contextos.

Resulta curioso en consecuencia constatar que la grafía $<\mathrm{AE}>$ del latín no recoja con toda seguridad ni la pronunciación real del diptongo /ai/ en latín (/e:/) ni la del griego (/a:/).

5.4. En lo que hace a los femeninos en -e (gr. - $\eta$ ) ya hemos comentado que su adaptación en latín debió de presentar necesariamente más dificultades que en el caso de los en $-a$.

La convención gráfica en este caso responde a la siguiente norma: la grafía $<\mathrm{H}>$ del griego equivale a $<\mathrm{E}>$ en latín.

Así, todos los nominativos de estos nombres responden a este uso: Acte (CIL II 1996), Aegiale (CIL II2/14, 58), Agile (CIL II2/14, 736), Anatole (CIL II2/14, 458), Astice (CIL II2/14, 525), etc.

Sin embargo, la situación de partida es distinta en el caso del dativo cuya norma en griego era $<\mathrm{HI}>$ aunque la grafía usual era $<\mathrm{H}>^{20}$. Por este motivo, en latín, contrariamente a lo señalado en el caso de los dativos en $<\mathrm{AI}>$ griegos, buena parte de los dativos de estos nombres femeninos en -e se transcriben con $<\mathrm{E}>$. Esto es lo que se ve en los ejemplos de dativo del tipo Crocale, Hedone, Tyche, en los que sólo podemos distinguir gráficamente este caso del nominativo si el ejemplo va acompañado de otros nombres que nos lo indiquen más claramente ${ }^{21}$.

Es interesante e importante señalar que hablamos en todo momento de nuevo en esta ocasión de convenciones gráficas que no coinciden necesariamente con la realidad fonética. Esto es especialmente evidente en este caso porque es muy posible que en griego la grafía $<\mathrm{H}>$ recubra ya un sonido $/ \mathrm{i} /$,

19 «On n'oubliera pas la pression sélective de la norme dans la morphologie et la protection graphique ou phonétique (morphographémie ou morphonologie) accordée aux morphèmes, qui en raison de leur charge informative, tolèrent l'ambiguïté minimale», Brixhe 2006, p. 16.

${ }^{20}$ A causa de nuevo de la monoptongación en griego del diptongo largo.

${ }^{21}$ Por ejemplo en los caso de Fabiae / Pieridi / Fabia / Crocale / filiae et sibi CIL II2/14, 158; Linia(!) / Atti(a)e / Hedone / CIL II2/5, 1046; D(is) M(anibus) / Iuliae Tyche / Iulia Amica / libertae CIL II2/14, 64, cf. Hispania Epigraphica on-line. 
evolución última de la /e/ larga. Nada de esto evidentemente queda reflejado en la adaptación latina de estos nombres propios femeninos en $-e$.

5.5. Teniendo en cuenta que el diptongo /ai/ en latín ${ }^{22}$ respondía a /e/, podemos suponer que finalmente los nombres propios femeninos de origen griego en - $\alpha$ y en - $\eta$ habrían conocido en latín algunas coincidencias en su flexión, en concreto en el caso de dativo, uno de los más empleados en las inscripciones sepulcrales. Así, un nombre como Thalia tendría en latín un genitivo y dativo Thaliae que respondería a una -e ([talie]) desde el punto de vista fonético y por su parte, un nombre como Tyche tendría al menos el mismo dativo. Este punto de unión podría haber supuesto la plena integración de los temas en -e en latín. Los puntos de contacto pueden ejemplificarse como sigue:

\section{Thalia (nom.) - Thaliae [-e (:)] (dat.)}

Tyche (nom.) - Tyche [-e (:)](dat.)

Parece lógico que el hablante de latín hubiera confundido ambas flexiones y que en consecuencia los nombres en - $e$ se hubieran integrado totalmente en la flexión de los femeninos en - $a$ en latín una vez que tuvieran este punto de unión. De hecho, resulta sorprendente que no haya sucedido así.

5.6. Uno de los motivos por los que no se produjo la adaptación esperable de estos nombres puede residir en el hecho de que en algunos casos parece claro que los femeninos en - $e$ se insertaron dentro de otro paradigma en latín. En efecto, algunos de estos nombres conocieron una declinación en nasal, de manera que no son raros los siguientes ejemplos de dativo de los nombres femeninos en -e: Glyceni, Didymeni, Chariteni, Spataleni, Staphyleni, Threpteni, Tycheni $i^{23}$.

No sabemos muy bien cuál es el origen de estas declinaciones en nasal, es decir, cuál es el paralelo sobre el que se asientan estas nuevas flexiones en -e, -enis. Se suele esgrimir el paralelismo que habría supuesto la declinación de los nombres propios latinos de origen griego ${ }^{24}$ masculinos (y algunos fe-

${ }^{22}$ Monteil 1984, p. 108.

${ }_{23}$ Por ejemplo en el caso de ]s sibi et Sta[tiae?] / Threpteni l(ibertae) su[ae] (CIL II2/14, 526 ), cf. Hispania Epigraphica on-line.

${ }^{24}$ Cf. Leumann 1977, p. 459. 
meninos ${ }^{25}$ ) en $-o$, -onis que heredan la flexión que tenían en griego y que también conocía el latín (cf. homo, -inis).

Sin embargo, no podemos descartar la posibilidad de que el origen de esta flexión hubiera tenido lugar en el propio griego tardío. Sabemos que ejemplos paralelos se atestiguan en el griego de Macedonia o en el de Egipto ${ }^{26}$ y que en griego tardío florecen los sufijos antroponímicos del tipo - $\tilde{\alpha} \varsigma,-\tilde{\alpha} \tau o \zeta$, $-\tilde{\alpha} \zeta,-\tilde{\alpha} v o \zeta ;-1 \zeta,-1 v o \zeta,-0 \tilde{\zeta} \zeta,-0 \tilde{v} v o \zeta,-0 \tilde{\zeta} \zeta,-0 \tilde{\tau} \tau \zeta^{27}$.

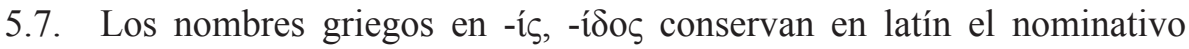
en -is, el genitivo en -idis y el dativo en -idi/-ide del tipo Chrysis, Chrysidis, Chrysidi/ Chryside. Tenemos, sin embargo, algún ejemplo de adaptación a los temas en - $a$, como es esperable: Crysidae (CIL II 1993, Almería). Se trata de la forma de dativo del mismo nombre pero declinado como tema en - $a$. Éste es el texto del documento y la traducción que puede verse en la página web de Hispania Epigraphica:

Politice an(norum) L / Crysidae an(norum) $V /$ Pusinnicae / an(norum) $\cdot V \cdot$ $h($ ic $) \cdot s($ itae $) \cdot s($ unt $) / s($ it $) \cdot t($ ibi $) \cdot t($ erra $) \cdot l($ evis $)$

«A Politice, de cincuenta años. A Crisida de cinco años. A Pusinica de cinco años. Aquí están enterradas. Que la tierra te sea leve».

Los dos primeros nombres de las difuntas son de origen griego. El prime-

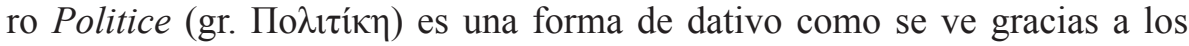
dos siguientes terminados en -ae. El segundo, Crysidae, presenta una grafía semiculta. Por un lado, la consonante aspirada del griego $/ \mathrm{kh} /$ aparece notada con la grafía de la sorda correspondiente y por otro la vocal /ü/ presenta la transcripción latina convencional y culta ${ }^{28}$.

6. Otra de las consecuencias originadas por la presencia de estos nombres propios en latín es la aparición en la lengua latina de sufijos, terminaciones, formaciones morfológicas desconocidas en esta lengua. Detectamos en consecuencia al menos los siguientes sufijos de nombres femeninos ajenos al latín:

${ }^{25}$ Cf. Más adelante el nombre de mujer Chelido: [.] Cal(purnius) Vitu[lus / Ver]giniae [- - - / - - ]e matri et / Chelidini uxori / [f(aciendum)] c(uravit) HEp 9, 1999, p. 296.

${ }^{26}$ Dubois 2010, pp. 398-400.

${ }^{27}$ Hay una discusión muy interesante sobre los sufijos -eni(s), -eti(s) (¿latinos?) en Adams 2003, pp. 486-490.

${ }^{28}$ Cf. las notas 16 y 17 para la transcripción de ambos sonidos. 


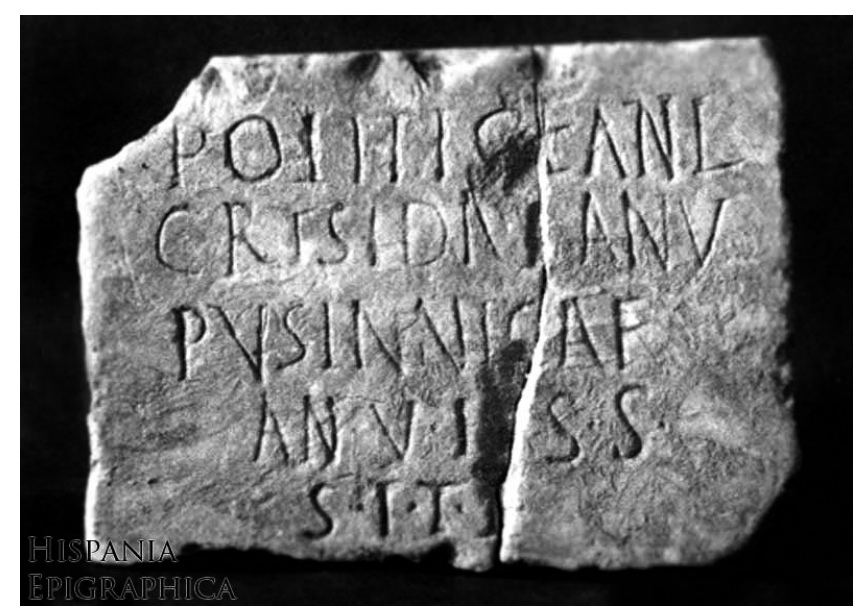

Imagen de la inscripción procedente del archivo de Hispania Epigraphica Online Database.

(a) -usa: Arescusa (CIL II 5905, CIL II2/5, 762, CIL II 6328b), Paezousa ${ }^{29}$ (CIL II2/14, 646) y Eutycusa (HEp 9, 1999, 91). Se trata de antiguas formaciones griegas de participio en los tres casos de los verbos ả

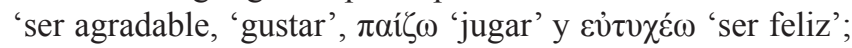

(b) -(i)o: Audiena Caritio, (CIL II 6188, gr. Xapítıv): se trata de un nombre griego procedente de una formación en género neutro, de uso frecuente para llamar a las mujeres y sobre todo a las niñas. Es una manera cariñosa de llamarlas semejante a nuestra forma de llamar a las niñas 'cosita...' 30 ;

(c) -o(n): Vinicia Chelido (CIL II 1422, CIL II 1789, HEp 9, 1999, 296, $\dot{\eta}$ $\chi \varepsilon \lambda 1 \delta \omega ́ v$, -óvos): es el nombre de la 'golondrina', atestiguado varias veces en los documentos hispanos;

(d) -mene: Clymene (CIL II 1996; HEp 12, 2002, 404). La terminación procede de las formaciones de participio femeninas mediopasivas del griego. En este caso se trata de una formación atemática del verbo $\kappa \lambda \hat{v} \omega$,

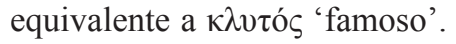

${ }^{29}$ La forma está parcialmente reconstruida en esta inscripción: Public[iae] / Paezu[sae.

${ }_{30}$ Masson 1989, pp. 45-52. 
(e) -tate: Philtate (CIL II2/14, 509; HEp 11, 2001, 320). Nos hallamos en esta ocasión ante la forma de superlativo del adjetivo pínos.

6.1. Hay ocasiones, sin embargo, en las que ambas lenguas, el latín y el griego, coinciden en sus formaciones. Esto no debe llamarnos la atención si tenemos en cuenta que ambas son lenguas indoeuropeas y por tanto derivan de un tronco común. Así sucede en el caso de los siguientes sufijos:

(f) - ulla: Antulla (cf. Anthyllus en Roma, CIL II 1401, CIL II2/14, 111, CIL II2/14, 278), se trata con toda probabilidad de un nombre derivado de őv $\theta$ os 'flor', con la grafía de la consonante sorda para la transcripción de la dental aspirada griega y la / ̈̈/ con otra de las convenciones utilizadas para ello.

(g) -ica/-e: Calchedonica, Astice, Ionice, Politice.

(i) -ina/-e: Alexandrina, Myrsine, Myrine.

Queremos llamar la atención sobre el último de los sufijos que vamos a mencionar. Se trata de una formación conocida tanto en latín como en griego, pero de orígenes diferentes, de tal forma que podríamos decir que nos hallamos ante una coincidencia derivada de la homonimia que presenta el sufijo en latín:

(j) -osa: Tryphosa (Aemiliae Tryphosae, RIT 501), Caretosa (=Charitosa; Memmiae / Caretosae CIL II 3307), Afrosa (=Aphrosa: p(osuit) Afrosa / IRCP 250).

El primero de los ejemplos responde a una formación de participio femenino griego del verbo $\tau \rho \vartheta \varphi \alpha ́ \omega, ~ \tau \rho v \varphi \tilde{\omega} \sigma \alpha$ 'vivir con lujo, disfrutar del lujo'. Sin embargo, en los otros dos casos, da la impresión de que la terminación -osa ha conocido cierta expansión en latín, quizá porque coincide con el sufijo abundancial en latín 'lleno de'. Así podríamos entender con algunas dudas $^{31}$ el ejemplo Caritosa, desconocido en Grecia, que podríamos traducir

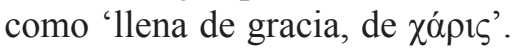

31 Podría tratarse de una forma enteramente latina derivada de caritas derivado del adjetivo carus. Así lo explica Becker 2009, p. 317 agrupando las formas Caritas, Caritosus, Caritosa. 
Por último, Aphrosa es un hipocorístico derivado del nombre de la diosa Afrodita. Este tipo de formaciones es frecuente en griego tardío ${ }^{32}$ en donde no es raro encontrar formas del tipo masc. А $\varphi \rho \tilde{a} \varsigma$, A nombres de Afrodita y Asclepio respectivamente. Sin embargo, la terminación en el caso de Aphrosa está ausente de la documentación epigráfica de Grecia y puede justificarse como resultado de la extensión de este sufijo en latín en formaciones femeninas en buena medida porque en la propia lengua latina ya existía esta misma terminación.

7. Si consultamos el estudio de Becker en lo que hace a los nombres propios griegos de la Península Ibérica (ss. VI-XII), podemos observar el siguiente hecho llamativo: la práctica totalidad de los nombres propios griegos presenta las terminaciones en -ius, -us, en el caso de los masculinos, mientras que los femeninos tienen -ia. No quedan ejemplos de nombres propios femeninos en $-e$ o en $-i s$, lo que demuestra que se ha producido sin ninguna duda una reducción drástica de las distintas formaciones que se hallaban presentes en las inscripciones de la Hispania romana. Los ejemplos son numerosos, basta con la revisión del índice final para percatarse de ello: Adelphius, Adelphia, Aegidius, Agamius, Agapius, Agricius, Alexius, Alexia, Ambrosius, Amelius, Amelia, Anastasius, Anastasia, etc. Las excepciones están representadas por nombres griegos muy conocidos que probablemente no se perdieron nunca del tipo Alexander y sus derivados.

8. De todo lo expuesto en nuestro estudio se deduce que los nombres propios femeninos (y con toda probabilidad también masculinos) de origen griego no llegaron a triunfar nunca en la lengua latina. Hemos podido comprobar que no se adaptaron a la estructura morfológica de los nombres propios latinos: las terminaciones griegas de los femeninos en $-e$ o en -is no se insertaron en los esquemas latinos y los diferentes sufijos griegos no conocieron ninguna expansión, no fueron productivos en latín. Casos como el de -osa fueron probablemente aislados.

Es muy probable en consecuencia que estos nombres propios siempre hubieran mantenido un aspecto extranjero, ajeno al latín entre los hablantes

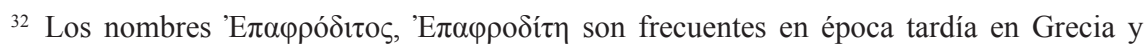
en Roma. Las formas abreviadas también se conocen en Grecia, cf. Dubois 2010, p. 417. Este tipo de hipocorísticos son también bastante frecuentes en Hispania: Alexa, Apolla, Epaphras, Asclas, Chelys (¿de Chelido?). 
de esta lengua. Esta conclusión justifica sin duda algo que ya nos había llamado la atención en el análisis de la adaptación fonética de estos nombres, y es el hecho de que hemos podido comprobar que en todo momento estos nombres se transcriben letra a letra de una lengua a la otra respetando las convenciones gráficas para estos casos, pero sin que en ningún momento se llegaran a escribir tal y como sin duda se pronunciaban. Así se ve en la adaptación de los nombres femeninos en $-a$ y en $-e$ griegos. Este estado de cosas justifica asimismo la ausencia casi absoluta de híbridos ${ }^{33}$, así como la falta de pervivencia de la variedad de estos nombres en épocas posteriores.

De ello se deduce que es muy posible que en ningún momento estos nombres propios hubieran salido del círculo cerrado de las personas de condición servil que solían llevarlos en la Hispania romana.

Estas conclusiones se pueden aplicar también al latín de Roma en cuyas inscripciones las transcripciones de los nombres griegos son esencialmente las mismas.

\section{BiBLIOGRAFíA}

Adams, J.N. 2003: Bilingualism and the Latin Language, Cambridge.

Bechtel, F. 1917 (HPN): Die historischen Personennamen des Griechischen bis zur Kaiserzeit, Halle.

Becker, L. 2009: Hispano-romanisches Namenbuch. Untersuchungen der Personenamen vorrömischer, griechischer und lateinisch-romanischer Etymologie auf der Iberischen Halbinsel im Mittelalter (6.-12. Jahrhundert), Tübingen.

Beltrán Fortes, J. 2013: «Greco-orientales en la Hispania republicana e imperial a través de las menciones epigráficas», en de Hoz, M ${ }^{\text {a }}$ P. y Mora, G. (eds.), El oriente griego en la Península Ibérica. Epigrafia e historia, Madrid.

Biville, Fr. 1990: Les emprunts du latin au grec. Approche phonétique, LouvaineParis.

Biville, Fr. 1995: Les emprunts du latin au grec. Approche phonétique II. Vocalisme et conclusions, Louvaine-Paris.

CIL II ${ }^{2}$ : Conventus Astigitanus (CIL II $2 / 5$; 1998); Cordubensis (CIL II $2 / 7$, 1995); Tarraconensis (CIL II $2 / 14$ fasc. 1, 1995 y CIL $\mathrm{II}^{2} / 14$ fasc. 2, 2011), bajo la dirección de G. Alföldy.

33 Ejemplos como (A)Polinidorus (IRC III, 175) considerados con acierto como un híbrido o una forma latinizada de Apollodoros son prácticamente inexistentes, cf. Curbera 1996, p. 293. 
Brixhe, Cl. 2006: «De la filiation à l'héritage. Réflexion sur l'origine des langues et des dialectes», en Brixhe, Cl. y Vottéro, G.,(dirs.), Peuplements et genèses dialectales dans la Grèce Antique, Paris, pp. 7-37.

Canós i Villena, I. 2002, L'epigrafia greca a Catalunya. Debrecen (SEG 52 nº1000). Curbera, J. 1996: «A curse tablet from Emporiae (IRC III 175)», ZPE 110, pp. 292-294. Curbera, J. 1997: «The Greek Curse Tablet of Emporion», ZPE 117, pp. 90-94.

Curbera, J. 2005: Reseña de la segunda edición ampliada y renovada de Solin 2003. Epigraphica 67, pp. 561-565.

Dubois, L. 2010: «Des anthroponymes en -ovs», en Catling, R. W. y Marchand, F. (eds.), Onomatologos. Studies in Greek Personal Names presented to Elaine Matthews, Oxford, pp. 398-421.

Fernández Leborans, Ma J. 1999: «El nombre propio», en Bosque, I. y Demonte, V. (dirs.), Gramática descriptiva de la lengua española. Vol. 1, Madrid, pp. 76- 128.

Fraser, F.P.M y Matthews, E. (LGPN) 1987-: A Lexicon of Greek Personal Names, Oxford, vol. I, II, IIIA, IIIB, IV, VA.

Hock, H.H. 1986: Principles of Historical Linguistics, Berlin, NewYork, Amsterdam.

Hoz, M P. de 1997: «Epigrafía griega en Hispania», Epigraphica 59, pp. 29-96 (SEG $\left.47 \mathrm{n}^{\mathrm{o}} 1533\right)$.

Kajanto, I. 1982: The Latin Cognomina, Roma.

Leumann, M. 1977: Lateinische Grammatik I, München.

Lozano Velilla, A. 1998: Die griechischen Personennamen auf der iberischen Halbinsel, Heidelberg.

Masson, O. 1973: «Les noms des esclaves dans la Grèce Antique», Actes du colloque 1971 sur l'esclavage, Paris, pp. 9-23 (Onomastica Graeca Selecta, vol. I, Paris 1990, pp.147-161).

Masson, O. 1985: «Le curieux nom d'un marseillais chez Aristote: Hermokaikoxanthos», J.Sav. 1, pp. 17- 23 (Onomastica Graeca Selecta, vol. I Paris 1990, pp. 475-481).

Masson, O. 1989: «Quelques noms de femme au neutre dans les inscriptions attiques», Horos 7, pp. 45-52 (Onomastica Graeca Selecta, vol. III, Paris 2000, pp. 61-68).

Monteil, P. 1984: Éléments de phonétique et de morphologie du latin, Paris.

Rodríguez Somolinos, H. 1998: «Inscriptiones graecae antiquissimae Iberiae», en Gangutia, E., La Península Ibérica en los autores griegos: de Homero a Platón, Madrid, pp. 333-362 (SEG $47 \mathrm{n}^{\circ} 1533$ ).

Solin, H. 1990: «Il nome Agathopus è nato in Africa?», en Mastino, A, (ed.), L'Africa romana. Atti del VII convegno di Studio Sassari, Sassari, 15-17 Dicembre 1989, Sassari.

Solin, H. 1996: Die stadtrömischen Sklavennamen. Ein Namenbuch I-III. Forschungen zur antiken Sklaverei, Beiheft 2, Stuttgart.

Solin, H. 2003: Die griechischen Personennamen in Rom. Ein Namenbuch. I, II, III, Zweite, vollig neu bearbeitete Auflage. CIL, Auctarium n.s. 2, Berlin - New York. 
Striano, A. 2004: «À propos de la nouvelle édition des inscriptions d' Hispania: deux notes anthroponymiques, Odephorus et Laurotiche», ZPE 147, pp. 225-228.

Striano, A. 2010: «Sycecale y Tricisma: los nombres propios de dos hermanas procedentes de una inscripción sepulcral de Tavira (Portugal)», Epigraphica 72, pp. 493-497.

Symeonidis, Ch. 1995: «Byzantinisch-neugriechische Namengebung (Byzantine and Modern Greek Name Giving / Dénomination byzantine-grecque moderne)» en Eichler, E. (ed.), Namenforschung /Name Sudies/Les Noms Propres: Ein Internationales Handbuch Zur Onomastik: An International Handbook of Onomastics: Manuel International D'onomastique, Handbücher zur Sprach-und kommunikationswissenschaft 11, Berlin, pp. 710-717.

Toribio, R. 2002: Morfología flexiva de los antropónimos griegos de la Hispania Tarraconensis, CIL II, XIV, 1, Madrid (inédito).

Páginas web

Hispania Epigraphica. Roman Inscriptions from the Iberian Peninsula: http://www.eda-bea.es/

Corpus Inscriptionum Latinarum II. Centro CIL II Alcalá de Henares: http://www2.uah.es/imagines_cilii/\#

Lexicon of Greek Personal Names: http://www.lgpn.ox.ac.uk/

Fecha de recepción de la primera versión del artículo: 12/12/2011

Fecha de aceptación: 12/12/2012

Fecha de recepción de la versión definitiva: 08/01/2013 